LACROIX, B. Ordre politique et ordre social objectivisme, objectivaction et analyse politique. In GRAWITZ, M. et LECA, J. (dir). Trait de Science Politique, vol 1. La science politique, science sociale, l'ordre politique. Paris: PUF 1985.

LACROIX, B. Le politiste et l' analyse des institutions: Comment parler de la présidence de la République. In LACROIX B.\& LAGROYE, J. Le président de la République Usages et genèses d'une institution. Presses de la fondation nationale des Sciences politiques, 1992

LANDE, C.H. Introduction: the dyadic politics: notes for a theory. In SCHMIDT, S. W. et al(eds) Friends, Followers and Factions; A reader in political clientelism. Berkley, University of California Press, 1977.

LEITE, D. B. C. e FRANCO, M. E. D. Faculda de de Direito de Porto Alegre (1900-1936) In Grupo de Estudos sobre Universidade. Reprodução e Recriação Social na Universidade e as ingerências do Estado: o caso da UFRGS. Porto Alegre, jan/1992.
MICELI, S. Intelectuais e Classe dirigente no Bra sil (1920-1945). São Paulo: Difel, 1979.

NEQUETE, L. (org). O Poder Judiciário no Rio Grande do Sul. Livro Comemorativo do centenário do Tribunal, a Relação de Porto Alegre e Tribunal e Justiça do Estado, Ed. TJ, 1974.

PÉCAUT, D. Os Intelectuais a Política no Brasil entre o povo e a nação. São Paulo: Ática, 1990.

SAINT MARTIN, M. Les Reconversions: Le exemple de la noblesse. In Les Élites: Formation, reconversion, internationalisation: Colloque Stockolm, sept/1993.

SOUTO, C. \& FALCÃO, J. Sociologia e Direito São Paulo: Pioneira, 1980.

VÊNANCIO FILHO, A. Das Arcadas ao Bacharelismo (150 Anos de Ensino jurídico no Brasil). 2. ed., São Paulo: Perspectiva, 1982.

VIANNA, L.W. et al. Corpo e Alma da Magis tratura Brasileira. 2. ed., Rio de Janeiro: Revan, 1997.

\title{
Como Pesquisar?
}

\section{Plaxniet Christiane Z2itschere}

Doutora pela Universidade de Hamburgo, Alemanha; Professora Visitante na Faculdade de Direito da UFRGS pelo programa CAPES/DAAD, março 1998 - maio 1999.

\begin{tabular}{|c|}
\hline 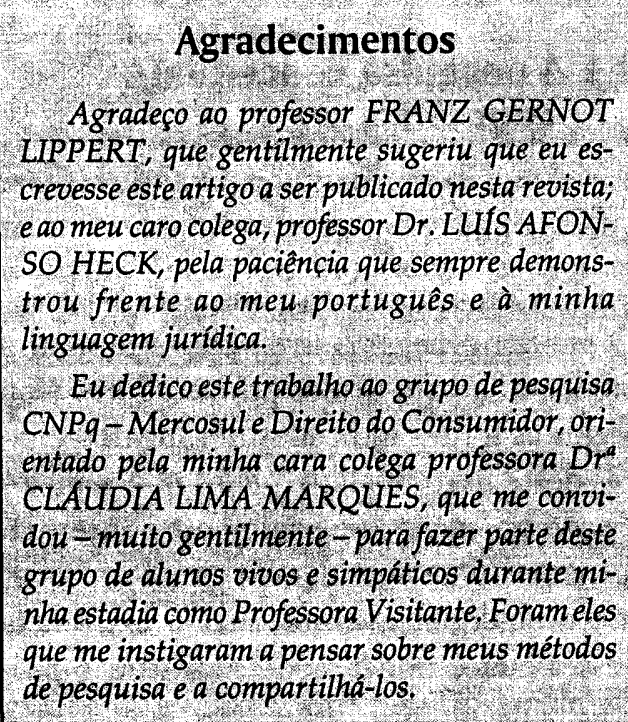 \\
\hline
\end{tabular}

(1) alestra para alunos de graduação e pós-graduação, realizada no dia 22.04.1999, na Faculdade de Direito da UFRGS, denominada: "Como pesquisar e navegar na pesquisa: uma introdução ao método alemão".

\section{Nota preliminar}

Este artigo destina-se, especialmente, aos alunos que começam a desenvolver o processo de pesquisa. Mas, talvez, seja também, em parte, interessante para os colegas professores, devido à cultura jurídica diferente na qual se formou a autora, oferecendo, desse modo, possivelmente, não só um outro enfoque sobre o tema, mas também idéias 'complementares para as orientações dos seus jovens pesquisadores.

\section{A questão da curiosidade e} o tema

Toda a pesquisa tem como base um interesse de buscar - ou uma visão da realidade jurídica ou uma explicação para essa 
realidade. São as perguntas: O quê? Como? Por quê? É a curiosidade que está no fundo dessas perguntas.

Mesmo que, no início, seja uma curiosidade genérica, podendo-se, assim, interessar por qualquer tema (incluindo temas de direito tributário ou previdenciário, que normalmente não despertam o interesse do estudante de Direito), é sempre melhor desenvolver um interesse específico. Pois, dessa maneira, vai sobreviver às horas escuras que cada pesquisador, jovem ou menos jovem, tem que enfrentar até chegar ao fim do seu trabalho.

Então, o primeiro passo, no desenrolar da pesquisa, ${ }^{1}$ é escolher um tema que desperte o seu interesse. É bem possível que o tema mude um pouco depois das primeiras leituras, ou que se chegue à conclusão de que o tema não deve ser seguido. Isso não significa nada sério, mas um processo normal do pensamento: cada desvio enriquece e deixa amadurecer o próprio pensamento. Na pesquisa, um erro, quando descoberto antes de publicar o trabalho, é sempre de valor.

\section{Como começar}

Dependendo dos conhecimentos individuais e do tamanho do trabalho vale a pena começar com a leitura de um livro básico, clássico sobre o tema, deixando sedimentar esta leitura na mente por um tempo. Este caminho recomenda-se se os conhecimentos ainda não são muito desen-

1. Aqui fala-se sobre pesquisa individual. É claro que também há pesquisa para um professor que precisa de ajuda de bolsistas. Neste caso, o primeiro passo é receber o tema do professor, talvez, já com as indicaç̌es da bibliografia correspondente. 2. Ver logo a seguir. volvidos ou - independentemente dos conhecimentos individuais - se o trabalho tem tamanho considerável.

No caso de um trabalho menor e conhecimentos individuais sobre o tema já avançados, pode-se logo começar com as fichas de leitura. ${ }^{2}$

\section{Tipos de pesquisa e métodos correspondentes}

Na pesquisa jurídica pode distinguirse um tipo "conceitual/dogmático" e um tipo "empírico". Também há formas mistas e vale ressaltar que toda pesquisa empírica precisa de uma parte conceitual. Entretanto, uma pesquisa conceitual/dogmática é teoricamente possível sem uma parte empírica.

\subsection{A pesquisa conceitual/ dogmática}

É o tipo mais simples para o acadêmico da cultura jurídica brasileira

Começa-se com a busca do material. O melhor é pegar o livro-chave e olhar bibliografia para títulos prometedores e/ou seguir as fontes indicadas nos lugares-chaves deste livro. É claro que os novos meios de comunicação, especialmente a Internet, fornecem uma abundância de informações sobre qualquer assunto, mas a existência desses meios nunca pode substituir o próprio pensamento. Entender e seguir uma obra-chave, por sua vez, abre o caminho para o pensamento próprio.
Ao ler o livro-chave e as outras fontes por ele indicadas deve-se começar com a produção das fichas de leitura. Esta não pode ser substituída por fotocópia (ou livro) riscada, porque escrever o conteúdo de um texto com suas próprias palavras já é meio caminho para uma produção própria de pensamento científico

A ficha pode ser feita no computador ou de modo manual em cartões, mas é aconselhável, mesmo quando feito no computador, imprimir as fichas.

A ficha deve sempre conter, no mí nimo: todos os dados bibliográficos, ${ }^{3}$ a área de direito geral, a área específica à qual pertence a obra analisada e a estrutura principal do seu conteúdo. Fichas bem feitas podem até substituir a obra analisada, podendo, com isso, ser utilizadas e aproveitadas por muitos anos.

Como, normalmente, uma ficha tem várias folhas, deve-se sempre anotar o número da folha e o número da ficha (que se refere ao número dentro da área específica à qual pertence a ficha). Vale a pena anotar, na primeira folha de uma ficha, o número de folhas que esta ficha tem.

Há pessoas que preferem uma ficha bibliográfica à parte para cada obra analisada, para levar à biblioteca, em cartões pequenos. Mas isso depende do gosto pessoal do pesquisador.

$\mathrm{O}$ uso de uma estrutura clara na ficha facilita esse processo. Eu, pessoalmen-

3. Estes devem incluir a biblioteca onde se encontra o livro e o número do catálogo.

4. Ver acima p. 3

5. Como exemplo, para este tipo de pesquisa, ver Cláudia Lima Marques/Harriet Christiane Zitscher (coordenadoras) e colaboradores, Relatório da Pesquisa Brasilcon sobre Seguro Saúde no TJRS de 1991 até maio de 1998, in: MARQUES, Cláudia Lima/ LOPES, José Reinaldo de Lima/PFEIFFER, Roberto Augusto Castelhanos, Saúde e Responsabilidade: seguros e planos de assistência privada à saúde, São Paulo: Editora Revista dos Tribunais, 1999, pp. 183-203. te, achei útil usar duas cores para melhor clareza. Neste caso, recomenda-se pegar cores simples (por exemplo, preto e azul) para poder seguir este padrão de trabalho em qualquer lugar.

O objetivo principal das fichas é cap. tar, entender e anotar o conteúdo da obra analisada, todavia, não faz mal já estabele. cer a crítica própria, se tiver, em cor diferente.

Ao final da produção das fichas é importante deixar sedimentar um pouco, relendo as fichas e considerar se precisa de mais fontes. Neste último caso, repetem-se os passos descritos acima, a partir do item $3.1 .^{4}$

As fichas, no âmbito da pesquisa conceitual/dogmática, podem tratar de livros e artigos, mas, também, dependendo do caso, de sentenças ou, até, de leis. Tudo, tendo em vista um melhor aproveitamento do material para futuras pesquisas.

Vale a pena marcar qual é o objeto da ficha, por exemplo, por meio da inserção de um "L" (livro), "A" (artigo), "S" (sentença) ou "N" (norma) num dos lados superiores da ficha e marcar esta letra com uma cor específica.

\subsection{A pesquisa empírica 5}

A pesquisa empírica pode ser feita com legislação, jurisprudência ou até petições iniciais e semelhantes. Porém, o tipo 
mais difundido e prometedor para resultados interessantes é a análise aprofundada de jurisprudência.

Começa-se com um livro-chave ou uma decisão sobre o assunto da pesquisa Colhe-se, na seqüência, toda a jurisprudência dentro dos limites definidos, como: as sunto, tribunal, período, meio de publicação. O levantamento deve ser exaus. tivo: é melhor limitar o assunto do que não ter toda a jurisprudência sobre o mesmo. Até pode ser válido limitar-se só às decisões jurisprudenciais publicadas na coletânea oficial de um certo tribunal, durante um ano. Porque a publicação na coletânea oficial já indica que o próprio tribunal jul. gou importante estas decisões e, por isso, valem para serem analisadas com profundidade.

O tipo das decisões colhidas depende também do enfoque concreto da pesquisa seguida.

Por exemplo, se o interesse do pesquisador for mais jurídico, é melhor concentrar-se nos acórdãos do Supremo Tribunal Federal publicados oficialmente sobre o assunto pesquisado. Se o interesse recair mais na repercussão social da jurisprudência pela atitude de juízes, ou por es pecialidades regionais, é melhor entrar nos arquivos de um tribunal devidamente escolhido, e buscar todas as decisões dentro de um determinado período. ${ }^{6}$
Estes exemplos expostos mostram dois métodos extremos, até opostos, com possibilidades intermediárias para a escolha e busca de um sample de casos para a pesquisa.

Ainda, vale a pena ressaltar: devese definir bem os critérios para o levantamento de casos para a pesquisa e, depois, averiguar tudo exaustivamente no sentido de se preencher os critérios definidos.

Uma vez colhidos todos os acórdãos em fotocópias há duas opções: ou primeiro ler todos e deixar sedimentar antes de produzir as fichas; ou, logo começar com as fichas.

Antes de começar com as fichas deve-se, porém, pensar, também neste caso, numa estrutura para elas. No mínimo, devem conter: todos os dados técnicos, como o tribunal, a turma, a data, o número do processo, o relator, se há voto vencido, etc., a base legal, os principais fatos, as fontes indicadas, o mérito. ${ }^{7}$ Além disso, sempre deve haver um lugar para observações adicionais na ficha. São os casos nos quais o tribunal se viu obrigado a enfrentar questões sociais difíceis ou conflituosas e que, por isso, são interessantes do ponto de vista jurídico. Eles, freqüentemente, demonstram, por exemplo, especialidades de método ${ }^{8}$ que valem a pena serem anotadas.

Dependendo do assunto e do interesse que orienta a pesquisa, pode-se incluir mais critérios para a análise ou para todos

6. Foi este o tipo de pesquisa empirica na cbra indicada na nota anterior

7. Para um trabalho que demonstra bem como é se basear em um sistema parecido de fichas de leitura, ver ARAÚJO, Nadja (Coord.) e colaboradores. Resumos de Jurisprudéncia de DIPR no STF e STJ, vol. I, Rio de Janeiro: Dep. de Direito, PUCRJ, ano II, n. 03, 1996.

8. Observaçăo da autora em anos de pesquisa jurisprudencial.

Revista da Faculdade de Direito da UFRGS, v. 17, 1999 os casos levantados ou para uma escolha específica de um grupo menor.

Como esta variação de pesquisa jurisprudencial é menos difundida no Brasil seguirá um exemplo dela pela autora. ${ }^{9}$

Foram levantados em tomo de quatrocentos acórdãos do Tribunal Federal alemão e dos seus tribunais precedentes no período de duzentos anos, que tratavam do status paternal. Todos estes acórdãos (publicados principalmente nas coletâneas oficiais) foram submetidos a uma análise simples, seguindo os pontos mencionados acima, além de citaçõeschave em cada caso, quando presentes.

Por meio de leitura cuidadosa de todos os acórdãos e de uma análise de legislação e de doutrina foram isolados os cem casos que marcaram o desenvolvimento do direito na área investigada e que podem ser vistos como linha de jurisprudência. Estes cem casos foram submetidos a uma análise mais profunda e detalhada. Foram consideradas as fontes de decisão (legislação, jurisprudência, doutrina), o estilo da argumentação, a "filosofia" no fundo da decisão (por exemplo, Positivismo ou Direito Natural), o padrão social desejado prevalecente (por exemplo, atitudes expostas pelos juízes sobre deveres morais) e a linguagem e coesão internas da argumentação. Todos esses pontos foram subdivididos em mais subpontos. Para dar só um exemplo: no âmbito da jurisprudência como fonte da decisão foram considerados, ainda, as referências aos fatos das decisões anteriores, ao mérito, aos argumentos, às palavras somen-

te, a grupos ou linhas de decisões anteriores ou à "opinião dominante", ao todo, configurando-se numa mescla de doutrina e jurisprudência. Além disto, foi considerada a discussão da jurisprudência antiga no sentido de aplicá-la ou não ou da não-aplicação tácita.

$\mathrm{Na}$ pesquisa empírica deve-se aproximar do material com mente aberta, porque os métodos de análise mais específicos só evoluem quando o pesquisador "entra" no material. Deste modo, os métodos aprofundam-se em cada passo. A pesquisa empírica sempre chega aos resultados finais, pelo menos, em parte, de maneira indutiva, do específico ao geral. ${ }^{10}$

\section{O preparo da produção}

Depois da busca e análise do material, seja no âmbito de uma pesquisa conceitual/dogmática, seja no de uma pesquisa empírica, prepara-se a própria produção do trabalho científico.

Deve-se pensar numa estrutura para a reprodução do pensamento próprio, que deve ser lógica. Além de preencher os prérequisitos formais quanto ao número de partes e subdivisões, a estrutura deve ser orientada pelas exigências do conteúdo da matéria.

Quando se elabora esta estrutura vale a pena agregar as fichas de leitura na ordem desta estrutura - e pensar bem e com calma se precisa mais material. Se este for o caso, devem-se repetir os passos anteriores

9. ZITSCHER, Harriet Christiane. Elterlicher Status in Richterrecht und Gesetzesrecht, Baden-Baden: Nomos, 1996.

10. Oraciocínio indutivo caracteriza-se pelo movimento do pensamento que vai de uma ou várias verdades singulares a uma verdade mais universal. (Para isso, ver JOLIVERT, Régis. Curso de Filosofia. Rio de Janeiro: Agir, 1987, p. 46 e seguintes)

Revista da Faculdade de Direito da UFRGS, v. 17, 1999 
no tocante à busca e análise do material. Se está pronto todo material, pode-se começar a escrever.

\section{A escrita do trabalho}

Muito importante em todo o trabalho científico é o fio condutor ou o fio ver melho (expressão traduzida do alemão roter Faden, que se refere ao mito de Ariadne e Teseu e o Minotauro no labirinto).

Este fio vermelho significa:

1. Sempre têm de coincidir título e conteúdo, não só em relação ao trabalho como um todo, mas tam bém, em referência a todo subtítulo ou capítulo em si.

2. O caminho do pensamento aberto pela "Introdução" deve ser fechado pela "Conclusão".

3. Cada frase deve basear-se na frase anterior e exigir a frase posterior como conseqüência lógica. $O$ que significa que não deve faltar nenhuma frase para seguir o raciocínio e não ter nenhuma frase supérflua.

Sempre ajuda a imaginar, como leitor, um leigo inteligente. Se ele não entende o trabalho de um pesquisador no início do seu caminho na pesquisa, é provável que o próprio pesquisador não entende realmente o que faz ou fez.

Invariavelmente deve-se indicar as fontes exatas: cada frase ou parágrafo que não é do próprio autor do trabalho precisa de uma fonte; cada vez que se menciona um nome no texto deve seguir uma refe- rência a uma fonte concreta na nota de rodapé.

Deve-se evitar um excesso de texto escrito nas notas de rodapé; se tiver mais de uma nota no trabalho que precisa como espaço meia página vale a pena repensar: ou se tira o excesso de texto da nota do trabalho ou se tira este excesso da nota para integrá-lo no texto do trabalho (para cada nota deve-se buscar solução individual).

\section{Revisão final}

$\mathrm{Na}$ Alemanha é muito comum, se não a regra, entregar o trabalho já revisado pelo autor a um amigo profissional para ele dizer se entende o trabalho e, também, para ele fazer uma última revisão do conteúdo. Além disso, normalmente, um outro amigo não-jurista ou um parente que tenha tempo e disposição faz uma revisão puramente lingüística. É verdade que esta revisão adicional custa tempo e paciência e depende da criação de um certo hábito deste tipo de apoio mútuo. Porém, contribui muito na melhora do trabalho, porque quem escreve, com freqüência, não tem distância suficiente para ver os próprios erros, sejam eles pequenos ou grandes.

\section{No fim, duas observações gerais}

Trabalho científico tem um ritmo próprio que varia de pesquisador a pesquisador, mas sempre faz parte uma alternação de fases de pensamento, busca e sedimentação. Especialmente as fases de sedimentação ajudam para a profundidade dos conhecimentos alcançada no fim do trabalho.
É importante ficar sempre aberto para discutir o que não se esperava: um pouco de preconceito pode ajudar na estrutura do tema e na orientação da pesquisa; mais do que isso, o preconceito limita a própria pesquisa. Nessa medida, ele deve ser substituído pela pré-compreensão. 